\title{
Keratin, Type I Cytoskeletal 19
}

National Cancer Institute

\section{Source}

National Cancer Institute. Keratin, Type I Cytoskeletal 19. NCI Thesaurus. Code C16488.

Keratin, type I cytoskeletal 19 (400 aa, $\sim 44$ kDa) is encoded by the human KRT 19 gene.

This protein plays a role in myofiber organization. 